\title{
Pulmonary Effects of Prolonged Oligohydramnios following Mid-Trimester Rupture of the Membranes - Antenatal and Postnatal Management
}

\author{
Olivia Williams $^{\mathrm{a}}$ Graham Hutchings $^{\mathrm{b}}$ Corinne Hubinont $^{\mathrm{b}} \quad$ Christian Debauche $^{\mathrm{a}}$ \\ Anne Greenough ${ }^{c}$ \\ Departments of a Neonatology, and ${ }^{\mathrm{b}}$ Obstetrics, Cliniques Universitaires Saint Luc, Université Catholique de \\ Louvain, Brussels, Belgium; ' Division of Asthma, Allergy and Lung Biology, King's College Hospital, Kings College \\ London, London, UK
}

\section{Key Words}

Pulmonary hypoplasia - Persistent pulmonary hypertension of the newborn - Preterm prelabour rupture of the membranes $\cdot$ Oligohydramnios

\begin{abstract}
Mid-trimester, preterm prelabour rupture of the membranes (PPROM) with prolonged oligohydramnios remains a challenge for both obstetricians and neonatologists. Although survival rates have improved, morbidity remains common particularly due to pulmonary insufficiency and pulmonary hypertension. The aetiology of abnormal lung development is unknown but may depend critically on pulmonary vascular development. Antenatal evaluation of at-risk foetuses by three-dimensional ultrasound and MRI is possible but the techniques need to be further assessed. Antenatal corticosteroids given in cases of PPROM reduce the incidence of neonatal death, respiratory distress syndrome, intraventricular haemorrhage and necrotising enterocolitis without increasing maternal or neonatal infection. The true risk-benefit ratio of antibiotics, tocolysis and strategies to normalise amniotic fluid volume remains less clear. There is no consen-
\end{abstract}

sus regarding the optimal ventilation strategy to support infants with pulmonary insufficiency following PPROM, and further work is required to determine whether and which pulmonary vasodilators improve long-term outcome in these infants.

Copyright $\odot 2011$ S. Karger AG, Basel

\section{Introduction}

Mid-trimester preterm prelabour rupture of the membrane (PPROM) occurs in approximately $0.4-0.7 \%$ of pregnancies [1]. It is associated with poor foetal outcome due mainly to the high risk of very premature delivery. The mean gestational age at delivery following mid-trimester PPROM ranges from 23 to 27 weeks, and there may be a long latency of greater than 14 days membrane rupture prior to the delivery of the infant. Following a prolonged period of oligohydramnios, there is an increased risk of cord compression, joint contractures, skeletal anomalies and pulmonary hypoplasia. The neonatal outcome following prolonged preterm rupture of the membranes has improved over the last decades. Early 
studies reported neonatal survival following rupture prior to 25 weeks to be $24 \%$ [2], whereas recent studies report increased survival rates of around 70\% [3-5]. Despite the reduction in mortality rates, the morbidity remains high, with $40 \%$ of survivors developing bronchopulmonary dysplasia (BPD). Infants born following rupture of the membranes prior to 24 weeks and a mean latency to delivery of 45 days had a fourfold increased risk of a composite adverse outcome (death, severe retinopathy of prematurity, BPD and severe neurological injury) when compared to age-adjusted controls [6]. The aim of this review is to evaluate critically the evidence regarding mechanisms of abnormal lung growth in PPROM and the efficacy of antenatal and postnatal diagnostic and therapeutic interventions.

\section{Lung Development following Oligohydramnios}

Following a period of prolonged oligohydramnios during mid-gestation, a proportion of infants develop pulmonary hypoplasia. Their lung to body weight ratio and total lung DNA are reduced and the radial alveolar count is decreased [7]. The pulmonary vascular bed is reduced in size with a decreased vessel count and increased pulmonary vascular muscular development $[8,9]$.

\section{Possible Mechanisms of Abnormal Lung Growth}

Mechanical Effects - Lung Fluid Production

Adequate lung fluid is essential for normal lung development. Initial theories regarding pulmonary hypoplasia development in PPROM were that reduced amniotic fluid volume would be associated with increased chest compression, reducing foetal breathing movements and causing an outflow ('squeeze') of lung fluid from the foetus. Subsequent studies, however, failed to confirm this, finding either reduced amniotic fluid pressure [10] or no change in either the amniotic or tracheal pressure [11].

In the rat, tracheal ligation resulted in a distension of the foetal lungs and an increased expression of growth factors, including insulin-like growth factor 1 , fibroblast growth factor 18 (FGF18) and connective tissue growth factor (CTGF), all vital for normal pulmonary growth. CTGF plays an important role in promoting alveolarisation and microvascular development in the later stages of foetal lung development [12]. It is theoretically possible therefore that a decrease in lung fluid may be associated with reduced production of these growth factors.
Foetal Breathing Movements

Foetal breathing movements are essential for normal lung growth. Decreased foetal breathing movements in the presence of prolonged oligohydramnios have been documented. This is likely to be multifactorial in origin and not purely as a result of thoracic compression from a lack of amniotic fluid. For example, cervical cord transection in the presence of oligohydramnios produced more severe pulmonary hypoplasia than cervical cord transection alone [13], suggesting that oligohydramnios independently affects lung development. In addition, PPROM is commonly associated with infection and inflammation, and these are known to reduce foetal breathing movements [14]. As well as gross breathing movements, fine peristaltic smooth muscle airway contractions have also been documented in the developing lung of various species [15], and these rhythmic contractions may create a flux of fluid in the lungs towards the distal lung buds. Therefore, both extrinsic and intrinsic muscle contractions in the lung create stretch and shear forces on foetal lung cells which have the capacity to regulate gene expression and alter both cell proliferation and differentiation (see below) [16].

Clinical studies of foetal breathing movements in pregnancies with prolonged oligohydramnios, however, have produced contradictory results. Some have identified the prolonged absence of foetal breathing movements as predictive for the development of pulmonary hypoplasia [17], whilst others have reported that foetuses affected by oligohydramnios spend significantly more time breathing than controls [11]. Foetuses have variable breathing efforts and may have periods of prolonged apnoea. Therefore, they should be observed over at least $2 \mathrm{~h}$ and on a number of occasions in order to determine reliably whether foetal breathing movements are present or not.

\section{Transcription and Growth Factors}

Foetal lung development is closely controlled by the sequential production of a large number of transcriptional regulators, and disruption of these has the potential to alter lung development. FGF and Sonic hedgehog play a role in determining the pattern of airway branching in mammalian lung development $[18,19]$. The lungs fail to develop in knockout mice lacking FGF10 [20]. Structural lung development is closely coupled to, and dependent on, normal vascular development. Vascular endothelial growth factor (VEGF) is a potent regulator of lung vascular growth and development, and also plays a role in the differentiation of type II pneumocytes and surfactant 
production [21]. Other factors implied in pulmonary vascular development include angiopoietins, endothelins and platelet-derived growth factor (PDGF); the latter is important in pulmonary vascular remodelling. Oligohydramnios induced in a rat model at the pseudoglandular stage of lung development resulted in reduced gene and protein expression of PDGF A and B, which was associated with smaller overall lung volumes and reduced alveolarisation [22].

In a study examining the expression of various proteins involved in angiogenesis in hypoplastic human lungs of various aetiologies, von Hippel-Lindau protein was expressed more frequently in the arterial smooth muscle cells of congenital diaphragmatic hernia (CDH) lungs but not in hypoplastic lungs following PPROM or renal agenesis [23]. Similarly, hypoxia-inducible factor-1a expression was reduced within the vasculature of $\mathrm{CDH}$ lungs but not in the hypoplastic lungs of other aetiologies. This suggests that the mechanisms of disrupted lung development may differ according to the underlying aetiology.

\section{Inflammation and Infection}

There is a high incidence of both acute and subacute infection following prolonged rupture of the membranes, but it is unclear as to whether this is in part responsible for the relatively high incidence of BPD (40\%) seen in these infants. In sheep models, endotoxin-simulated chorioamnionitis has been associated with a beneficial effect on lung maturation, increased epithelial surface area and airspace volume, improved compliance and increased surfactant production [24]. However, there is a detrimental effect on pulmonary vascular development such as smooth muscle hypertrophy of the distal pulmonary arterioles and decreased production of endothelial nitric oxide synthase, VEGF and platelet endothelial cell adhesion molecule-1 $[25,26]$. These effects are likely to be mediated by cytokines such as interleukin- 6 and tumour necrosis factor- $\alpha$ [27], and the vascular changes observed are similar to those in BPD and in severe pulmonary hypoplasia.

The clinical link between chorioamnionitis and BPD is uncertain. Wattenberg et al. [28] reported a higher incidence of BPD following chorioamnionitis, but there have been at least 18 subsequent studies investigating the relationship between BPD and chorioamnionitis and in those in which multivariate adjustment has been undertaken, no significant difference in BPD risk related to chorioamnionitis was demonstrated. In a recent casecontrol study, chorioamnionitis was associated with an increased risk of BPD but only if the infants subsequent- ly developed postnatal infection or required mechanical ventilation for more than 7 days. This led the authors to postulate a 'double hit' theory for BPD development [29]. Therefore, the relatively high incidence of BPD in the context of prolonged oligohydramnios may be related to a combination of altered antenatal lung development, infection, inflammation and the effects of postnatal respiratory management.

\section{Antenatal Prediction of Pulmonary Hypoplasia}

A variety of reference ranges for normal lung biometry have been established using two-dimensional ultrasound, but none reliably predict pulmonary hypoplasia. More recently, three-dimensional ultrasound has been used to identify pulmonary hypoplasia in at-risk foetuses. In a recent series [30], a sensitivity of between 85 and $92 \%$ for predicting pulmonary hypoplasia was achieved when the results were adjusted for gestational age, estimated foetal weight and two-dimensional biometric measurements. In foetuses with varying risks of pulmonary hypoplasia such as those with $\mathrm{CDH}$ or anterior abdominal wall defects, the results of 3-D ultrasound significantly correlated with the durations of ventilation and supplementary oxygen dependency [31]. An MRI study demonstrated that foetuses exposed to PPROM had decreased lung volume measurements and decreased signal intensity in $\mathrm{T}_{2}$-weighted images [32]. As well as reduced lung volume, these babies may also exhibit persistent pulmonary hypertension of the newborn (PPHN). Prediction of PPHN is difficult to assess before birth. Despite this, reduced diastolic and systolic velocities in the pulmonary arteries have been demonstrated by Doppler examination of foetuses affected by pulmonary hypoplasia [33], but measurements can be technically difficult in the absence of amniotic fluid. A combination of clinical, biometric and Doppler parameters may be most predictive in identifying lethal pulmonary hypoplasia. Although antenatal prediction may be useful in guiding management and counselling parents, it should be noted that a lethal outcome is also dependent on the postnatal management including intention to treat and level of neonatal care offered.

\section{Antenatal Management}

The management of mid-trimester PPROM centres on efforts to prolong safely the pregnancy in an effort to improve neonatal outcome [1], although this should be bal- 
anced against a possible increase in risk of maternal morbidity. Potential complications include infection, thromboembolic events, and an increased incidence of both caesarean section and placenta acreta [34].

\section{Surveillance of Infection}

Clinical signs of chorioamnionitis and serum markers such as an elevated white cell count and an increased high-sensitivity serum C-reactive protein are used to identify infection. There is, however, a concern that intrauterine infection may predate the appearance of clinical and biological signs. For these reasons, it has been suggested that amniocentesis should be undertaken to identify infection at an early stage, either routinely at first presentation following PPROM or at the development of subtle clinical signs such as uterine sensitivity. Microbiological examination of the amniotic fluid, bacterial culture and a raised lactate dehydrogenase and decreased glucose in the amniotic fluid are used to identify if infection is present [35]. Amniocentesis, however, may provoke preterm birth, and sterile amniotic fluid does not exclude the possibility of choridecidual infection [36].

\section{Antibiotic Therapy}

Approximately $30-75 \%$ of cases of PPROM are associated with low-grade chorioamnionitis. Women with PPROM also have a higher incidence of abnormal colonisation of the lower genital tract than matched controls [37]. Studies therefore have been undertaken to determine whether antibiotics following PPROM might reduce the risk of foetal and maternal infection, prolong the pregnancy and improve neonatal outcome. In the ORACLE I study, the efficacy of erythromycin and/or amoxicillin clavulanate was compared to placebo in women with PPROM without overt signs of infection. Oral erythromycin following PPROM was associated with prolongation of pregnancy, less use of surfactant, lower proportions of infants being oxygen dependent at 28 days and 36 weeks post-menstrual age, fewer cerebral abnormalities and fewer positive blood cultures [38]. Follow-up data, however, did not show any significant differences in outcomes between the two groups [39]. Current American College of Obstetricians and Gynecologists' guidelines do recommend routine use of antibiotics following PPROM, but the short-term benefits need to be balanced against the lack of evidence for either long-term benefit or improved perinatal mortality.

\section{Corticosteroids}

Antenatal corticosteroids should be given to women presenting with PPROM prior to 32 weeks as they reduce the incidence of neonatal death, respiratory distress syndrome, intraventricular haemorrhage, necrotising enterocolitis and the duration of respiratory support, without increasing maternal or neonatal infection [40], although the evidence for a beneficial effect below 26 weeks' gestational age is less clear [41].

\section{Tocolysis}

Therapeutic tocolysis may result in a slight delay before delivery allowing for the administration of corticosteroids, but a beneficial effect has not been demonstrated [42].

\section{Normalising Amniotic Fluid Volume}

Amnioinfusion

In small retrospective studies, serial amnioinfusions were not reported to have adverse effects. In those pregnancies in which the amniotic fluid index remained elevated for more than $48 \mathrm{~h}$ after amnioinfusion (approximately $25 \%$ of cases) [43], the outcome in terms of neonatal survival, incidence of pulmonary hypoplasia and neurological anomalies were better than if the oligohydramnios persisted [44]. Serial invasive procedures, however, increase the risk of infection or provoking bleeding; in the absence of positive results from randomised trials, this procedure cannot be recommended.

\section{Amnioplugging}

Various agents have been used experimentally to reseal the leak of fluid following spontaneous membrane rupture. Hydrogel sealant was applied successfully to the cervical canal in a case of prelabour rupture of membranes at 20 weeks of gestation [45]. Transvaginally applied intracervical fibrin sealant prior to 24 weeks of gestation resulted in increased amniotic fluid volume in 10 patients and apparent resealing in 2 patients from a total of 12 cases treated [46]. The use of gelatin sponge (Gelfoam) administered into the amniotic cavity in order to plug the cervical canal has been successfully used in cases of PPROM. The overall neonatal survival rate, however, was 40\% [47]. Amnioplugging has been used successfully following invasive foetal techniques. An amniopatch consisting of platelets and cryoprecipitate may be injected into the amniotic fluid [48], and the addition of platelets and plasma improved port site occlusion and repair following foetoscopy [49]. 
Promotion of Foetal Lung Growth and Development

In animal models, tracheal occlusion led to the buildup of lung fluid with gradual expansion of the lungs and increased lung growth [50]. Tracheal occlusion in foetuses with $\mathrm{CDH}$ increased lung growth and enhanced lung development [51]. In pregnancies with oligohydramnios due to PPROM, however, this procedure would be technically more difficult due to the reduced access and manoeuvrability at foetoscopy.

Retinoids, derived from vitamin A, are essential for normal lung development. They promote alveologenesis and induce alveolar regeneration. Administration of maternal retinoic acid in a nitrofen-induced $\mathrm{CDH}$ model promoted lung growth and alveologenesis [52]. The administration of retinoic acid in an 'oligohydramnios-induced' pulmonary hypoplasia rat model, however, did not have a positive effect on pulmonary growth or differentiation [53].

Tetrandrine is a bisbenzylisoquinolone alkaloid with a variety of antihypertensive, antioxidant and anti-inflammatory effects. In a $\mathrm{CDH}$ model, tetrandrine reversed foetal lung immaturity and normalised thickened pulmonary vascular walls. It also decreased the levels of transforming growth factor- $\beta_{1}$ which are raised in $\mathrm{CDH}$ models and have been implicated in the development of pulmonary hypoplasia [54]. No data are available related to its use in the context of prolonged oligohydramnios.

\section{Neonatal Management}

\section{Diagnosis}

In infants with pulmonary hypoplasia, lung function is abnormal at birth with reduced tidal volume, increased respiratory rate and reduced static lung compliance and functional residual capacity. The gold standard to confirm pulmonary hypoplasia is a lung to body weight ratio of less than 0.015 at postmortem [55] with reduced radial alveolar count or total DNA count [7]. Characteristic findings on the chest radiograph are of a small bellshaped chest with raised hemi-diaphragms and clear lung fields, although 'clear lung fields' may be masked by radiographic signs of respiratory distress in prematurely born infants. A radiographic diagnosis may be supported by clinical findings of an infant unresponsive to ventilatory support and exogenous surfactant therapy. Echocardiography is an essential investigation both to confirm the diagnosis of PPHN and to guide subsequent management.

Pulmonary Hypoplasia following

Prolonged Oligohydramnios

\section{Management}

A high level of neonatal intensive care is likely to be necessary, and delivery should take place, where possible, in a tertiary neonatal centre. Initial aggressive management should be attempted even if the infant shows signs of severe respiratory failure compatible with pulmonary hypoplasia. It is recognised that a subset of infants suffer from isolated PPHN, which responds well to immediate ventilatory and pulmonary vasodilator therapy with relatively few long-term complications $[3,56]$.

The optimal ventilatory management of infants born following prolonged oligohydramnios and exhibiting signs of pulmonary hypoplasia remains to be defined. There is a theoretical advantage of high-frequency ventilation (HFOV) amongst infants suffering from pulmonary hypoplasia, as it provides the possibility of optimal alveolar recruitment whilst reducing the risk of excessive barotrauma. Retrospective case series appear to show a beneficial effect of HFOV in the management of $\mathrm{CDH}$ [57]. The use of HFOV in the context of pulmonary hypoplasia following PPROM has not been formally evaluated, although a positive effect has been proposed in a number of retrospective reviews $[3,56]$. In addition, there is evidence that HFOV augments the response to inhaled nitric oxide (iNO) in cases of PPHN [58].

Pulmonary hypertension is common in infants with pulmonary hypoplasia following PPROM. In some small case series, a short-term positive effect following administration of iNO therapy was highlighted $[3,59,60]$. A recent subset-analysis of the infants enrolled in the PiNO trial found that infants born with suspected pulmonary hypoplasia following PPROM who received iNO had a trend towards increased survival and a reduced incidence of BPD and IVH, but the numbers were too small to be subjected to meaningful statistical analysis [61]. Randomised studies are needed to assess the value of iNO and other pulmonary vasodilators in this group of preterm infants. iNO promotes distal lung growth in experimental models following hyperoxia exposure or specific VEGF inhibition [62, 63]. Prolonged low-dose iNO for the prevention of BPD has been explored in a general preterm population, but was found to be unsuccessful $[64,65]$. There are case reviews describing the successful use of bosetan, milrinone and iloprost as alternative vasodilators in a preterm population [66-68], but further randomised controlled studies are necessary in order to define the value and safety of these more novel therapies in such a population.

Preterm infants born following mid-trimester PPROM may also suffer from respiratory distress syn- 
drome, and 'conventional' surfactant therapy is indicated. Infants with severe pulmonary hypoplasia, however, may fail to show a positive response to surfactant therapy alone.

Due to the high incidence of neonatal infection following prolonged oligohydramnios, appropriate investigations should be undertaken, and treatment with broadspectrum antibiotics is mandatory if an infection with an unknown pathogen is suspected.

Supplementation with vitamin A has a modest positive effect on both mortality and on the incidence of BPD (OR 0.93) [69]. The effect, however, has not been explored in infants with pulmonary hypoplasia following PPROM. Recent animal work suggests that the positive effects of vitamin A on lung growth septation and capillary growth are mediated by a reduction in elastin deposition and an upregulation of various vascular growth factors [70]. Further studies are needed to ex- plore the efficacy of treatment in specific groups of prematurely born infants.

In conclusion, mid-trimester PPROM with a prolonged latency to delivery remains a challenge for both obstetricians and neonatologists. Despite improvements in neonatal outcome, mortality and morbidity remain high, and there are few long-term data for infants born in this context. Further research is needed in order to understand the pathophysiological mechanisms causing pulmonary disease and to identify optimal antenatal and postnatal management strategies.

\section{Acknowledgements}

Dr. Olivia Williams is funded by the Catholic University of Louvain (fonds du patrimoine), LIVE-Belgium, a special grant from Baron Frère and Fetus for Life.

\section{References}

1 Waters TP, Mercer BM: The management of preterm premature rupture of the membranes near the limit of fetal viability. Am J Obstet Gynecol 2009;201:230-240.

-2 Taylor J, Garite TJ: Premature rupture of membranes before fetal viability. Obstet Gynecol 1984;64:615-620.

3 Williams O, Hutchings G, Debieve F, Debauche C: Contemporary neonatal outcome following rupture of membranes prior to 25 weeks with prolonged oligohydramnios. Early Hum Dev 2009;85:273-277.

4 Everest NJ, Jacobs SE, Davis PG, Begg L, Rogerson S: Outcomes following prolonged preterm premature rupture of the membranes. Arch Dis Child Fetal Neonatal Ed 2008;93:F207-F211.

$\checkmark 5$ Lindner W, Pohlandt F, Grab D, Flock F: Acute respiratory failure and short-term outcome after premature rupture of the membranes and oligohydramnios before 20 weeks of gestation. J Pediatr 2002;140:177182.

-6 Soylu H, Jefferies A, Diambomba Y, Windrim R, Shah PS: Rupture of membranes before the age of viability and birth after the age of viability: comparison of outcomes in a matched cohort study. J Perinatol 2010;30: 645-649.

7 Wigglesworth JS, Desai R: Use of DNA estimation for growth assessment in normal and hypoplastic fetal lungs. Arch Dis Child 1981 56:610-615.

-8 Jakkula M, Le Cras TD, Gebb S, Hirth KP, Tuder RM, Voelkel NF, Abman SH: Inhibition of angiogenesis decreases alveolarization in the developing rat lung. Am J Physiol Lung Cell Mol Physiol 2000;279:L600-L607.
9 Barth PJ, Ruschoff J: Morphometric study on pulmonary arterial thickness in pulmonary hypoplasia. Pediatr Pathol 1992;12:653-663.

10 Nicolini U, Fisk NM, Rodeck CH, Talbert DG, Wigglesworth JS: Low amniotic pressure in oligohydramnios - is this the cause of pulmonary hypoplasia? Am J Obstet Gynecol 1989;161:1098-1101.

11 Dickson KA, Harding R: Fetal breathing and pressures in the trachea and amniotic sac during oligohydramnios in sheep. J Appl Physiol 1991;70:293-299.

12 Mesas-Burgos C, Nord M, Didon L, Eklöf AC, Frenckner B: Gene expression analysis after prenatal tracheal ligation in fetal rat as a model of stimulated lung growth. J Pediatr Surg 2009;44:720-728.

13 Adzick NS, Harrisson MR, Glick PL, Villa RL, Finkbeiner W: Experimental pulmonary hypoplasia and oligohydramnios: relative contributions of lung fluid and fetal breathing movements. J Pediatr Surg 1984;19:658665.

14 Goldstein I, Romero R, Merrill S, Wan M, O'Conor TZ, Mazor M, Hobbins JC: Fetal body and breathing movements as predictors of intraamniotic infection in preterm premature rupture of membranes. Am J Obstet Gynecol 1988;159:363-368.

15 Jesudason EC: Airway smooth muscle: an architect of the lung? Thorax 2009;64:541-545.

16 Liu M, Tanswell K, Post M: Mechanical force-induced signal transduction in lung cells. Am J Physiol Lung Cell Mol Physiol 1999;277:667-683.
17 Blott M, Greenough A, Nicolaides KH, Moscoso G, Gibb D, Campbell S: Fetal breathing movements as predictor of favourable pregnancy outcome after oligohydramnios due to membrane rupture in second trimester. Lancet 1987;2:129-131.

18 Maeda Y, Dave V, Whitsett JA: Transcriptional control of lung morphogenesis. Physiol Rev 2007;87:219-244.

19 Pepicelli CV, Lewis PM, McMahon AP: Sonic hedgehog regulates branching morphogenesis in the mammalian lung. Curr Biol 1998;8:1083-1086.

20 Sekine K, Ohuchi H, Fujiwara M Yamasaki M, Yoshizawa T, Sato T, Yagishita N, Matsui D, Koga Y, Itoh N, Kato S: Fgf10 is essential for limb and lung formation. Nat Genet 1999; 21:138.

21 Compernolle V, Brusselmans K, Acker T, Hoet P, Tjwa M, Beck H, Plaisance S, Dor Y, Keshet E, Lupu F, Nemery B, Dewerchin M, Van Veldhoven P, Plate K, Moons L, Collen D, Carmeliet P: Loss of HIF-2alpha and inhibition of VEGF impair fetal lung maturation, whereas treatment with VEGF prevents fatal respiratory distress in premature mice. Nat Med 2002;8:702-710

$\checkmark 22$ Chen CM, Wang LF, Chou HC, Lang YD: Oligohydramnios decreases platelet-derived growth factor expression in fetal rat lungs. Neonatology 2007:92:187-193.

$\checkmark 23$ De Rooij j, Hosgor M, Ijzendoorn Y, Rottier R, Groenman F, Tibboel D, De Krijger R: Expression of angiogenesis-related factors in lungs of patients with congenital diaphragmatic hernia and pulmonary hypoplasia of other causes. Pediatr Dev Pathol 2004;7: 468-477. 
24 Willet KE, Jobe AH, Ikegami M, Brennan S, Newnham J, Sly PD: Antenatal endotoxin and glucocorticoid effects on lung morphometry in preterm lambs. Pediatr Res 2000;48:782-788.

25 Kallapur SG, Bachurski CJ, Le Cras TD, Joshi SN, Ikegami M, Jobe AH: Vascular changes following intra-amniotic endotoxin in preterm lamb lungs. Am J Physiol Lung Cell Mol Physiol 2004;287:L1178-L1185.

-26 Kunzmann S, Speer CP, Jobe AH, Kramer BW: Antenatal inflammation induces TGFbeta 1 but suppressed CTGF in preterm lungs. Am J Physiol Lung Cell Mol Physiol 2007;292:L223-L231.

-27 Kramer BW: Antenatal inflammation and lung injury: prenatal origin of neonatal disease. J Perinatol 2008;28(suppl 1):S21-S27.

28 Watterberg KL, Demers LM, Scott SM, Murphy S: Chorioamnionitis and early inflammation in infants in whom bronchopulmonary dysplasia develops. Pediatrics 1996;97: 210-215.

-29 Prendergast M, May C, Broughton S, Pollina E, Milner AD, Rafferty GF, Greenough A: Chorioamnionitis, lung function and bronchopulmonary dysplasia in prematurely born infants. Arch Dis Child Fetal Neonatal Ed 2011;96:F270-F274.

-30 Vergani P, Andreani M, Greco M, Farina G, Fedeli T, Cuttin S: Two- or three-dimensional ultrasonography: which is the best predictor of pulmonary hypoplasia? Prenat Diagn 2010;30:834-838.

- 31 Prendergast M, Rafferty GF, Davenport M, Persico N, Jani J, Nicoliades K, Greenough A: Three dimensional ultrasound fetal lung volumes and infant respiratory outcome: a prospective observational study. BJOG 2011;118: 608-614.

- 32 Kasprian G, Brugger PC, Helmer H, Langer M, Balassy C, Prayer D: Fetal lung development on MRT. Normal course and impairment due to premature rupture of membranes. Radiologe 2006;46:120-127.

33 Laudy JA, Gaillard JLJ, Van den Anker JN, Tibboel D, Wladimiroff J: Doppler ultrasound imaging: a new technique to detect lung hypoplasia before birth? Ultrasound Obstet Gynecol 1996;7:189-192.

34 Burstein E, Sheiner E, Mazor M, Carmel E, Levy A, Hershkovitz R: Identifying risk factors for premature rupture of membranes in small for gestational age neonates: a population-based study. J Matern Fetal Neonatal Med 2008;21:816-820.

35 Porreco RP, Heyborne KD, Shapiro H: Amniocentesis in the management of preterm premature rupture of the membranes: a retrospective cohort analysis. J Matern Fetal Neonatal Med 2008;21:573-579.

36 Grigsby PL, Novy MJ, Waldorf KM, Sadowsky DW, Gravett MG: Choriodecidual inflammation: a harbinger of the preterm labor syndrome. Reprod Sci 2010;17:85-94.
37 McGregor JA, French JI, Richter R, FrancoBuff A, Johnson A, Hillier S, Judson FN, Todd JK: Antenatal microbiologic and maternal risk factors associated with prematurity. Am J Obstet Gynecol 1990;163:14651473.

38 Kenyon SL, Taylor DJ, Tarnow-Mordi W: ORACLE Collaborative Group. Broad-spectrum antibiotics for preterm, prelabour rupture of fetal membranes: the ORACLE I randomised trial. ORACLE Collaborative Group. Lancet 2001;357:979-888.

39 Kenyon S, Pike K, Jones DR, Brocklehurst P, Marlow N, Salt A, Taylor DJ: Childhood outcomes after prescription of antibiotics to pregnant women with preterm rupture of the membranes: 7-year follow-up of the ORACLE I trial. Lancet 2008;372:1310-1318.

40 Roberts D, Dalziel S: Antenatal corticosteroids for accelerating fetal lung maturation for women at risk of preterm birth. Cochrane Database Syst Rev 2006;3:CD004454

41 Onland W, de Laat MW, Mol BW, Offringa $\mathrm{M}$ : Effects of antenatal corticosteroids given prior to 26 weeks' gestation: a systematic review of randomized controlled trials. Am J Perinatol 2011;28:33-44.

42 Mercer BM: Is there a role for tocolytic therapy during conservative management of preterm rupture of the membranes? Clin Obstet Gynecol 2007;50:487-496.

-43 Tan LK, Kumar S, Jolly M, Gleeson C, Johnson P, Fisk NM: Test amnioinfusion to determine suitability for serial therapeutic amnioinfusion in midtrimester premature rupture of membranes. Fetal Diagn Ther 2003; 18:183-189.

44 Locatelli A, Ghidini A, Verderio M, Andreani M, Strobelt N, Pezzullo J, Vergani P: Predictors of perinatal survival in a cohort of pregnancies with severe oligohydramnios due to premature rupture of membranes at $<26$ weeks managed with serial amnioinfusions. Eur J Obstet Gynecol Reprod Biol 2006;128:97-102.

45 Breathnach F, Daly S, Griffin E, Gleeson N: Intracervical application of synthetic hydrogel sealant for preterm prelabor rupture of membranes: a case report. J Perinat Med 2005;33:458-460.

46 Sciscione AC, Manley JS, Pollock M, Maas B, Shlossman PA, Mulla W, Lankiewicz M, Colmorgen GH: Intracervical fibrin sealants: a potential treatment for early preterm premature rupture of the membranes. Am J Obstet Gynecol 2001;184:368-373.

47 O’Brien JM, Barton JR, Milligan DA: An aggressive interventional protocol for early mid-trimester premature rupture of the membranes using gelatin sponge for cervical plugging. Am J Obstet Gynecol 2002;187: 1143-1146.

48 Lewi L, Van Schoubroeck D, Van Ranst M, Bries G, Emonds MP, Arabin B, Welch R, Deprest J: Successful patching of iatrogenic rupture of the fetal membranes. Placenta 2004;25:352-356.
49 Liekens D, Lewi L, Jani J, Heyns L, Poliard E, Verbist G, Ochsenbein-Kölble N, Hoylaerts M, Deprest J: Enrichment of collagen plugs with platelets and amniotic fluid cells increases cell proliferation in sealed iatrogenic membrane defects in the foetal rabbit model. Prenat Diagn 2008;28:503-507.

-50 Keramidaris E, Hooper SB, Harding R: Effect of gestational age on the increase in fetal lung growth following tracheal obstruction. Exp Lung Res 1996;22:283-298.

-51 Doné E, Gucciardo L, Van Mieghem T, Jani J, Cannie M, Van Schoubroeck D, Devlieger R, Catte LD, Klaritsch P, Mayer S, Beck V, Debeer A, Gratacos E, Nicolaides K, Deprest $\mathrm{J}$ : Prenatal diagnosis, prediction of outcome and in utero therapy of isolated congenital diaphragmatic hernia. Prenat Diagn 2008; 28:581-591.

52 Montedonica S, Sugimoto K, Felle P, Bannigan J, Puri P: Prenatal treatment with retinoic acid promotes pulmonary alveologenesis in the nitrofen model of congenital diaphragmatic hernia. J Pediatr Surg 2008;43: 500-507.

53 Chen CM, Chou HC, Wang LF, Lang YD, Yeh $\mathrm{CY}$ : Retinoic acid fails to reverse oligohydramnios-induced pulmonary hypoplasia in fetal rats. Pediatr Res 2007;62:553-558.

-54 Xu C, Liu W, Chen Z, Wang Y, Xiong Z, Ji Y: Effect of prenatal tetrandrine administration on transforming growth factor-B1 level in the lung of nitrofen-induced congenital diaphragmatic hernia. J Pediatr Surg 2009; 44:1611-1620.

-55 De Paepe ME, Friedman RM, Gundogan F, Pinar H: Postmortem lung/bodyweight standards for term and preterm infants. Pediatr Pulmonol 2005;40:445-448.

56 Kilbride HW, Thibeault DW: Neonatal complications of preterm premature rupture of membranes. Pathophysiology and management. Clin Perinatol 2001;28:761-785.

57 Cacciari A, Ruggeri G, Mordenti M, Ceccarelli PL, Baccarini E, Pigna A, Gentili A: High-frequency oscillatory ventilation versus conventional mechanical ventilation in congenital diaphragmatic hernia. Eur J Pediatr Surg 2001;11:3-7.

58 Kinsella JP, Abman SH: Inhaled nitric oxide and high frequency oscillatory ventilation in persistent pulmonary hypertension of the newborn. Eur J Pediatr 1998;157(suppl 1): S28-S30.

59 Pellowski A, Finer N, Etches P, Tierney A, Ryan A: Inhaled nitric oxide for premature infants after prolonged rupture of the membranes. J Pediatr 1995;126:450-453.

60 Uga N, Ihii T, Kawase Y, Arai H, Tada H: Nitric oxide inhalation therapy in very lowbirthweight infants with hypoplastic lung due to oligohydramnios. Pediatr Int 2004;46: $10-14$. 
61 Chock VY, Van Meurs KP, Hintz SR, Ehrenkranz RA, Lemons JA, Kendrick DE, Stevenson DK: NICHD Neonatal Research Network. Inhaled nitric oxide for preterm premature rupture of membranes, oligohydramnios and pulmonary hypoplasia. Am J Perinatol 2009;26:317-322.

-62 Tang JR, Markham NE, Lin YJ, McMurtry IF, Maxey A, Kinsella JP, Abman SH: Inhaled nitric oxide attenuates pulmonary hypertension and improves lung growth in infant rats after neonatal treatment with a VEGF inhibitor. Am J Physiol Lung Cell Mol Physiol 2004;287:L344-L351.

63 Lin YJ, Markham NE, Balasubramaniam V, Tang JR, Maxey A, Kinsella JP, Abman SH: Inhaled nitric oxide enhances distal lung growth after exposure to hyperoxia in neonatal rats. Pediatr Res 2005;58:22-29.
64 Mercier JC, Hummler H, Durrmeyer X, Sanchez-Luna M, Carnielli V, Field D, Greenough A, Van Overmeire B, Jonsson B, Hallman M, Baldassarre J: EUNO Study Group. Inhaled nitric oxide for prevention of bronchopulmonary dysplasia in premature babies (EUNO): a randomised controlled trial. Lancet 2010;376:346-354.

65 Kinsella JP, Cutter GR, Walsh WF, Gerstmann DR, Bose CL, Hart C, Sekar KC, Auten RL, Bhutani VK, Gerdes JS, George TN, Southgate WM, Carriedo H, Couser RJ, Mammel MC, Hall DC, Pappagallo M, Sardesai S, Strain JD, Baier M, Abman SH: Early inhaled nitric oxide therapy in premature newborns with respiratory failure. $\mathrm{N}$ Engl J Med 2006;355:354-364.

66 Radicioni M, Bruni A, Camerini P: Combination therapy for life-threatening pulmonary hypertension in a premature infant first report on bosentan use. Eur J Pediatr 2011, Epub ahead of print.
67 Danhaive O, Margossian R, Geva T, Kourembanas S: Pulmonary hypertension and right ventricular dysfunction in growth-restricted, extremely low birth weight neonates. J Perinatol 2005;25:495-499.

68 Eifinger F, Sreeram N, Mehler K, Huenseler C, Kribs A, Roth B: Aerosolized iloprost in the treatment of pulmonary hypertension in extremely preterm infants: a pilot study. Klin Padiatr 2008;220:66-69.

69 Darlow BA, Graham PJ: Vitamin A supplementation to prevent mortality and short and long-term morbidity in very low birth weight infants. Cochrane Database Syst Rev 2007;CD000501.

70 Albertine KH, Dahl MJ, Gonzales LW, Wang ZM, Metcalfe D, Hyde DM, Plopper CG, Starcher BC, Carlton DP, Bland RD: Chronic lung disease in preterm lambs: effect of daily vitamin A treatment on alveolarization. Am J Physiol Lung Cell Mol Physiol 2010; 299:L59-L72. 